\title{
Implications of Diabetes Mellitus on Minor Oral Surgical Procedures - A Questionnaire Survey Among Undergraduate Student Practitioners
}

\author{
Ashwin Shravan Kumar ${ }^{1}$ and Madhulaxmi $\mathrm{M}^{2}$ \\ ${ }^{1}$ Saveetha Dental College and Hospitals, Saveetha Institute of Medical \\ and Technical Sciences, Saveetha University, Chennai- 600077, India \\ ${ }^{2}$ Professor, Department of Oral and Maxillofacial Surgery, Saveetha Dental College and Hospitals, \\ Saveetha Institute of Medical and Technical Sciences,Saveetha University, Chennai - 600077, India
}

\section{ABSTRACT}

Diabetes mellitus is a common metabolic disorder in which the impaired leukocyte function and the metabolic abnormalities lead to inadequate migration of neutrophils and macrophages to the wound, along with reduced chemotaxis. Such cellular changes would predispose individuals to an increased risk of wound infection. To minimize the risk of an intraoperative emergency, clinicians need to have thorough knowledge about the disease before initiating any dental treatment. The aim of this study is to evaluate the difference in understanding between final year dental students and interns towards diabetes and its implications in oral surgical procedures. A questionnaire-based survey consisting of 15 questions was circulated via an online platform, survey planet. 100 participants who were dental students were included in the study. Responses were tabulated and Chi-square analysis was performed using SPSS software version 20.0.The results showed significant difference in approach towards diabetes between both the survey groups with $\mathrm{p}=0.001<$ 0.05. Whether continuing medical education programmes or altered teaching planner will help in better understanding and comprehensive patient management needs to be evaluated with further studies

\section{KEY WORDS: DIABETES MELLITUS, DENTAL, EXTRACTION, COMPLICATIONS, MANAGEMENT.}

\section{INTRODUCTION}

Diabetes mellitus is a chronic illness which has microvascular and macrovascular complications reported in many works of literature across the globe from a very long time (Bergman, 2007). Patients with diabetes mellitus have impaired leukocyte activation which makes them prone to many infections. In such patients surgical

\section{ARTICLE INFORMATION}

*Corresponding Author: madhulaxmi@saveetha.com Received 24th June 2020 Accepted after revision 11th August 2020 Print ISSN: 0974-6455 Online ISSN: 2321-4007 CODEN: BBRCBA

Thomson Reuters ISI Web of Science Clarivate Analytics USA and Crossref Indexed Journal

\section{Clarivate
Analytics}

NAAS Journal Score 2020 (4.31) SJIF: 2020 (7.728)

A Society of Science and Nature Publication,

Bhopal India 2020. All rights reserved.

Online Contents Available at: http//www.bbrc.in/

Doi: http://dx.doi.org/10.21786/bbrc/13.7/99 procedures might lead to sepsis. Oral surgical procedures ranging from simple extraction to complex fracture management may need to be done under antibiotic cover to prevent postoperative infections (Rothwell and Richard, 1984; Chakravarthy, 2013).

Based on statistics available, the majority of the world population are suffering from type 2 diabetes mellitus(DM), in which the South Asian population holds a major count. In India around $1 / 2$ the population are hyperglycemic and fall under the category of prediabetic whereas $1 / 4$ are diabetic(Kidambi and Patel, 2008; Sarwono, 2008). There are certain oral findings which can be an indicator for diabetes mellitus. Periodontal disease has been reported severely in patients with type 1 and type 2 diabetes. Even though the mechanism of diabetes on the periodontal ligament is not completely understood. Chronic periodontitis may be considered as an indicator

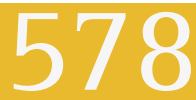


of long standing history of diabetes mellitus(Hariharan et al., 2019). However there are various other factors that help in identifying diabetic patients apart from history taking which should be practiced by student practitioners to avoid complications. The factors include knowledge on oral indicators of diabetes mellitus, various testing parameters like fasting and random blood sugar values, glycosylated hemoglobin (HbA1c), difficulties and management of post operative complications and the duration, type and dosage of antibiotic coverage during treatment (Adeyemi et al., 2019).

There are various studies that have provided information regarding implications and management of diabetes in a dental setup ( $\mathrm{S}$ and Choudhury, 2012; Vesterinen et al., 2012; Jankhwala, Singh and Nayak, 2014). But there needs an in-depth understanding and focus towards this aspect among student practitioners as they have a comparatively lesser experience in treating such patients. With such a high prevalence and burden of the disease, especially in Indian subcontinent it is essential that all healthcare professionals managing these patients are well aware about the implications and the potential adverse effects of the disease. With a rich case bank established over 3 decades we have been able to publish extensively in our domain (Abdul Wahab et al., 2017a; Eapen, Baig and Avinash, 2017; Patil et al., 2017a; Jain and Nazar, 2018a; J et al., 2018a; Marimuthu et al., 2018a; Wahab et al., 2018; Abhinav et al., 2019; Ramadorai, Ravi and Narayanan, 2019a; Senthil Kumar et al., 2019a; Sweta, Abhinav and Ramesh, 2019a)(Abdul Wahab et al., 2017b; Eapen, Baig and Avinash, 2017; Patil et al., 2017b; Jain and Nazar, 2018b; J et al., 2018b; Marimuthu et al., 2018b; Wahab et al., 2018; Abhinav et al., 2019; Ramadorai, Ravi and Narayanan, 2019b; Senthil Kumar et al., 2019b; Sweta, Abhinav and Ramesh, 2019b). Based on this inspiration we aim to compare the knowledge about the implications of diabetes mellitus on minor oral surgical procedures and the approach towards diabetic patients among the undergraduate dental students.

\section{MATERIAL AND METHODS}

This is a questionnaire based survey study among undergraduate students. Data were collected by reviewing the response of participants. Only dental undergraduate final year and intern students were included in the survey. Specialist dentists and preclinical students were excluded. The total sample size was 150 which accounted for 76 final year students and 74 intern students. All data retrieved were compiled in an excel sheet and imported to SPSS Version 20 by IBM for statistical analysis. Chi-square test with $\mathrm{p}$ value $<0.05$ was considered statistically significant.

\section{RESULTS AND DISCUSSION}

The study population included 150 students of which 76 were pursuing final year and 74 were attending internship respectively and all the participants had a good hands on experience treating diabetic patients. Figure-1 representing the association of participants and number of diabetic patients they attend to in a month. $60 \%$ students in both the study groups treat approximately 20 diabetic patients every month. Though most participants claimed that they knew normal sugar values (Figure 2), it was evident that final year students were more precise in their values than interns who had varied opinions (Figure 3) .

Figure 1: Bar graph representing the association between participants and number of patients with diabetic mellitus handled, where X-axis is participants year of study (Final year, Intern), Y-axis: Responses for the number of diabetic patients handled ( Blue-15 patients; Green-20 patients; Grey-25 patients; Violet-30 patients). There was no statistically significant difference in the number of diabetic patients handled by both the categories by Chi-square test with $\mathrm{p}=0.736>0.05$.

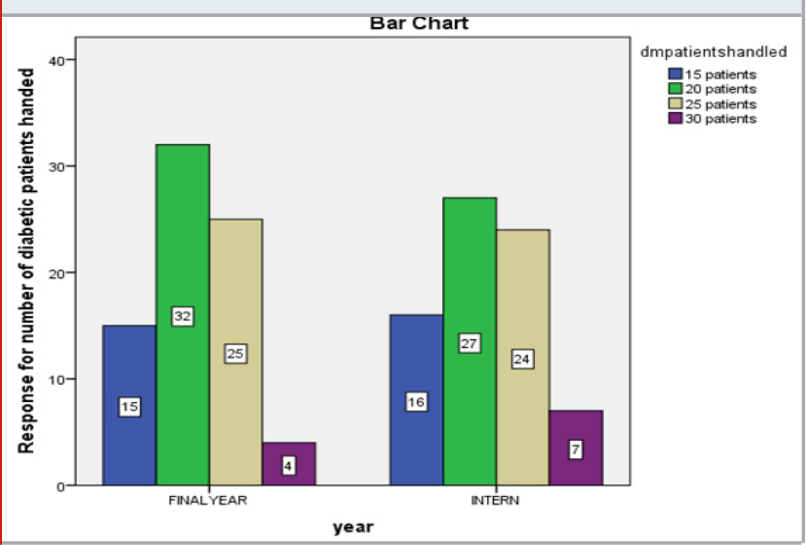

Figure-2 Bar graph representing the association between participants and response for awareness about blood sugar values, where X-axis: Year of study (Final year, Intern), Y-axis: Responses for the awareness about blood sugar values ( Blue-No; Green-Yes). There was no statistically significant difference in the knowledge about blood sugar values by both the categories by Chi-square test with $\mathrm{p}$ $=0.672>0.05$

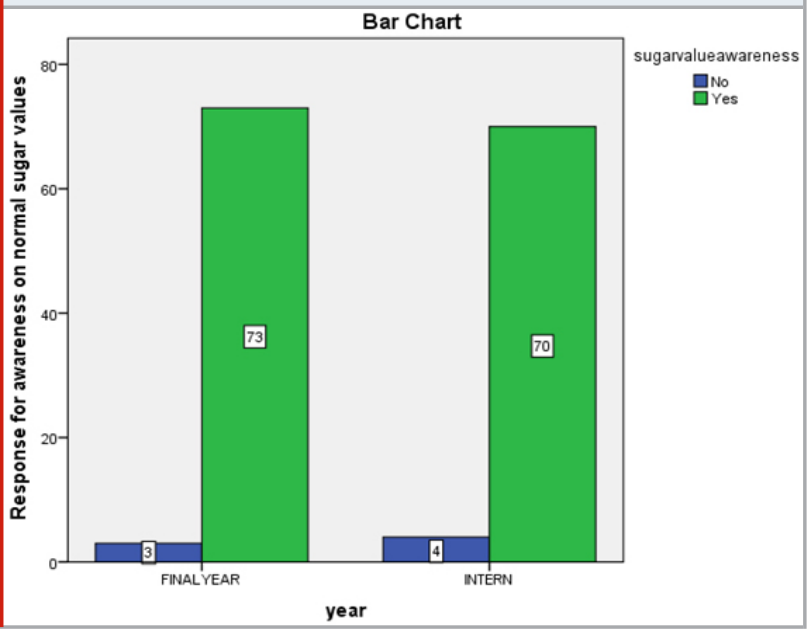


Figure 3: Bar graph representing the association between participants and response for awareness about Fbs values, where X-axis: Year of study (Final year, Intern), Y-axis: Responses for the normal Fbs value( Blue-70-90mg/dl; Green-80-110 mg/dl; Grey-90-120 mg/dl).There was statistically significant difference in the knowledge about blood sugar ranges by both the categories by Chi-square test with $\mathrm{p}=0.001<0.05$.

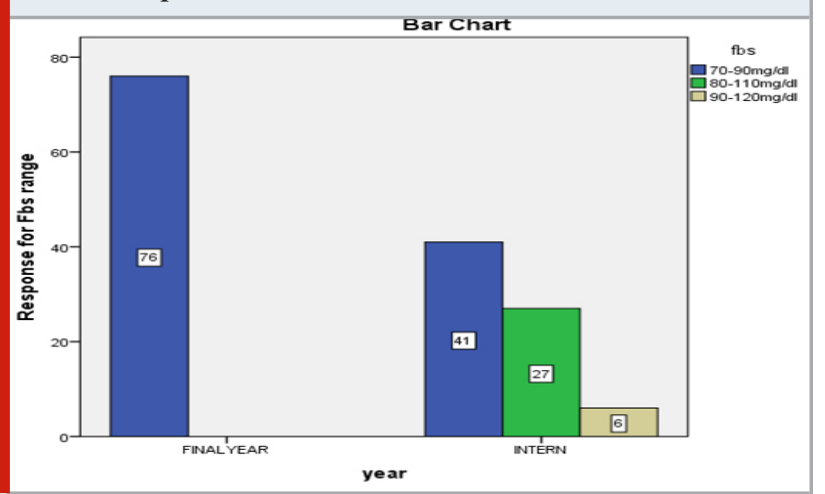

The association between participants and response to most difficult complications to be managed in diabetic showed that students from both study years thought candidiasis and ludwig's angina as common complications (Figure 4). However, the frequent secondary complication in diabetic patients following minor surgical procedures as per studies include non healing and dry socket due to dislodgement of clot especially in mandibular region due to atherosclerosis caused by long standing diabetes mellitus(DM) (Akinbami and Godspower, 2014). The same was reported when asked if they had themselves managed any post treatment complication in their diabetic patient and what was the most common complication the participants had encountered (Figure 5 \& 6 ).

Figure-4 Bar graph representing the association between participants and response for most difficult complication of diabetes in oral surgical procedures, where $\mathrm{X}$-axis: Year of study (Final year, Intern), Y-axis: Responses for the most difficult complication of diabetes in oral surgical procedures( Blue-All; Green-Candidiasis; Grey-Ludwig's angina; Violet-Mucormycosis; Yellow-Osteonecrosis).There was statistically significant difference in the knowledge about most difficult complication of diabetes in oral surgical procedures by both the categories by Chi-square test with $\mathrm{p}=0.0301<0.05$.

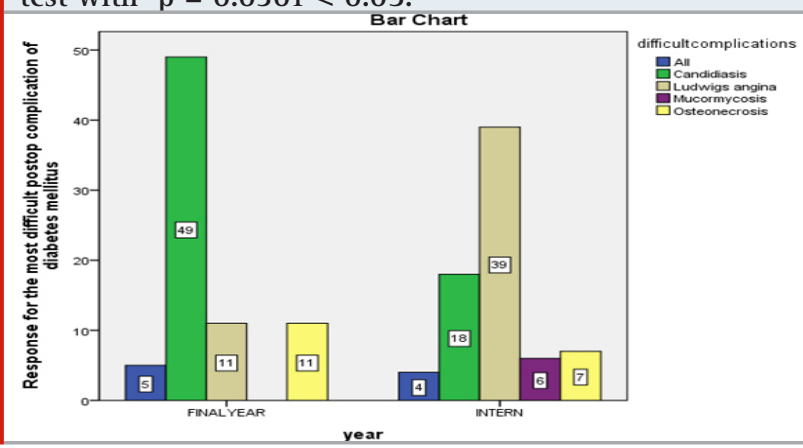

Figure 5: Bar graph representing the association between participants and response for complications handled, where X-axis: Year of study (Final year, Intern), Y-axis: Responses for the complications handled( BlueNo; GreenYes).There was a statistically significant difference in the experience in handling complications by both the categories by Chi-square test with $\mathrm{p}=0.018<0.05$.

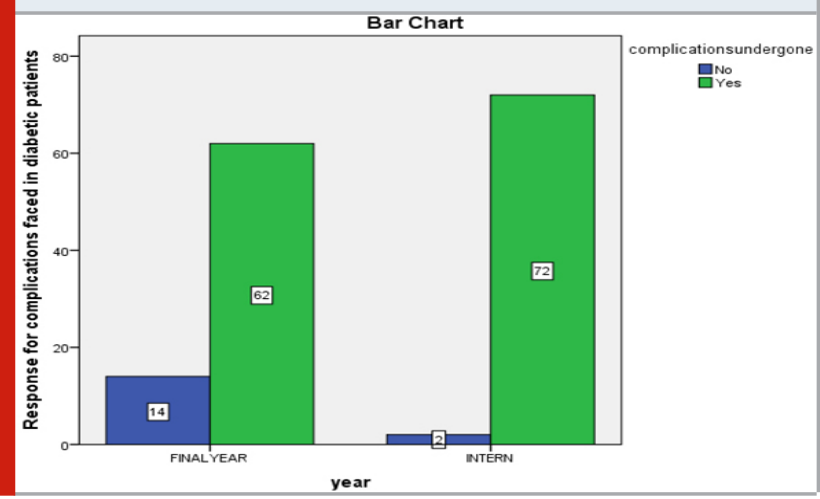

Figure 6: Bar graph representing the association between participants and response for most common complications of diabetes in oral surgical procedures, where $\mathrm{X}$-axis: Year of study (Final year, Intern), Y-axis: Responses for the most common complication of diabetes in oral surgical procedures( Blue-Dry socket; Green-Non healing Socket; Grey-0steonecrosis). There was no statistically significant difference in the experience for most common complications of diabetes in oral surgical procedures by both the categories by Chi-square test with $p=0.4701$ $>0.05$.

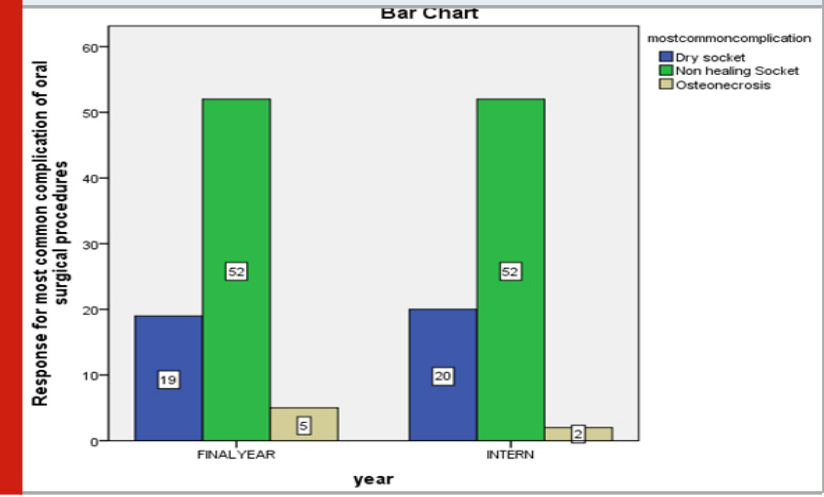

This shows the lack of correlating practical observation and knowledge to theory among students. The next set of questions was management of dental emergencies in diabetic patients and antibiotic cover for treatment. $90 \%$ of participants preferred referring patients to a hospital for physician consent. (Figure-7 \& 8). Since the diabetic patients are immunocompromised the need for prophylactic antibiotics can be debatable and hence an experienced oral and maxillofacial surgeon can provide adequate care under a prophylactic coverage. Since the patient has seeked a dental treatment, it would be preferable to refer such patients to a maxillofacial surgeon when in doubt (Darré et al., 2008). Similar 
studies conducted (Schaberg and Norwood, 2002; Dagogo-Jack, 2003, 2005; Fasanmade, Ogunsakin and Dagogo-Jack, 2019) also indicated identical results that many practitioners lacked complete knowledge about diabetes mellitus.

Figure 7: Bar graph representing the association between participants and response for decision in dental emergencies, where $\mathrm{X}$-axis: Year of study (Final year, Intern), Y-axis: Responses for the decision in dental emergencies( Blue-Refer to Hospital; Green-Refer to OMFS; Grey-Refer to Physician).There was a statistically significant difference in the decisions made in dental emergencies by both the categories by Chi-square test with $\mathrm{p}=0.027<0.05$.

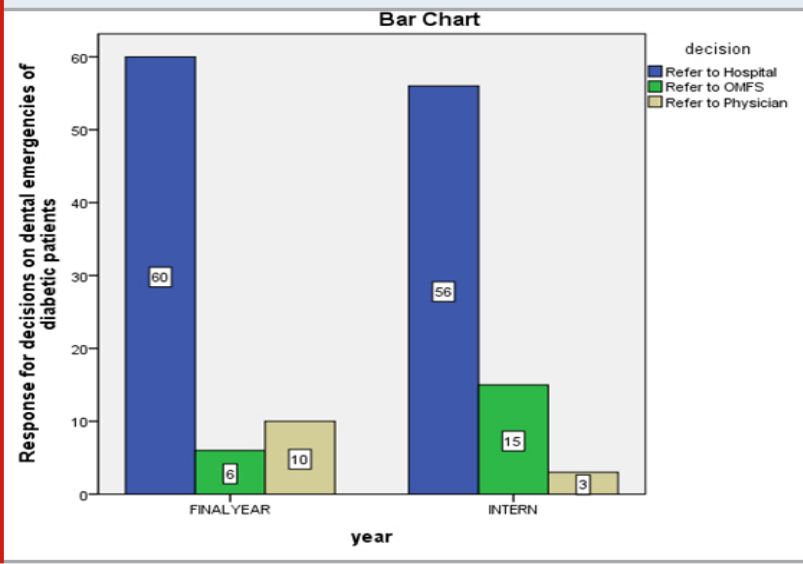

Figure 8: Bar graph representing the association between participants and response for decision in getting a physician consent, where X-axis: Year of study (Final year, Intern), Y-axis: Responses for the decision in getting a physician consent( Blue-No; Green-Yes).There was no statistically significant difference in the decisions for getting physician consent by both the categories by Chisquare test with $\mathrm{p}=0.895>0.05$.

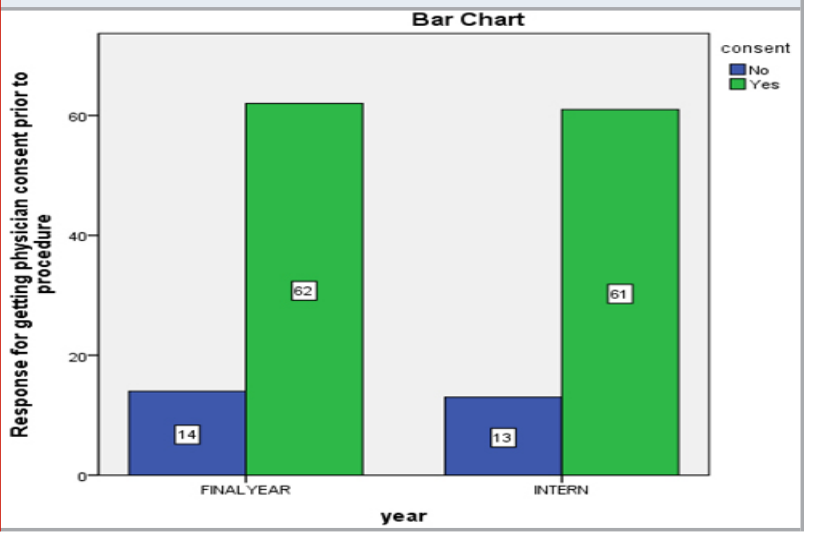

95\% of participants used antibiotic coverage in all their diabetic patients for all minor surgical procedures, prophylactically and also postoperatively (Figure 9 \& 10). This is in accordance with studies stating the sepsis occurring even during minor oral surgical procedure due to moist environment and patients with long standing diabetes are prone to conditions like endocarditis which may be life threatening and hence prophylaxis by antibiotics is necessary(Benvenga et al., 2019).Thus majority of the participants of aware of such complications and were preferring antibiotics. Antibiotics are of different categories and are of different mechanisms of actions and there is an arguable point regarding the providing of the right group of antibiotic coverage with minimal adverse effects. The most preferred antibiotic for oral infections is the penicillin group with or without metronidazole as the indication may be (Tong and Rothwell, 2000; Ghosh, 2019). The survey result was in consensus with this evidence, wherein $70 \%$ of the participants preferred amoxicillin as the prophylactic coverage (Figure 11). But, operative care in case of diabetic patients does not stop with antibiotics as the disease by itself possesses a very vague pathophysiology.

Figure 9: Bar graph representing the association between participants and response for decision in prescribing antibiotic coverage, where $\mathrm{X}$-axis: Year of study (Final year, Intern), Y-axis: Responses for the decision in prescribing antibiotic coverage( Blue-No; Green-Yes). There was no statistically significant difference in the decisions for prescribing antibiotics by both the categories by Chi-square test with $\mathrm{p}=0.265>0.05$.

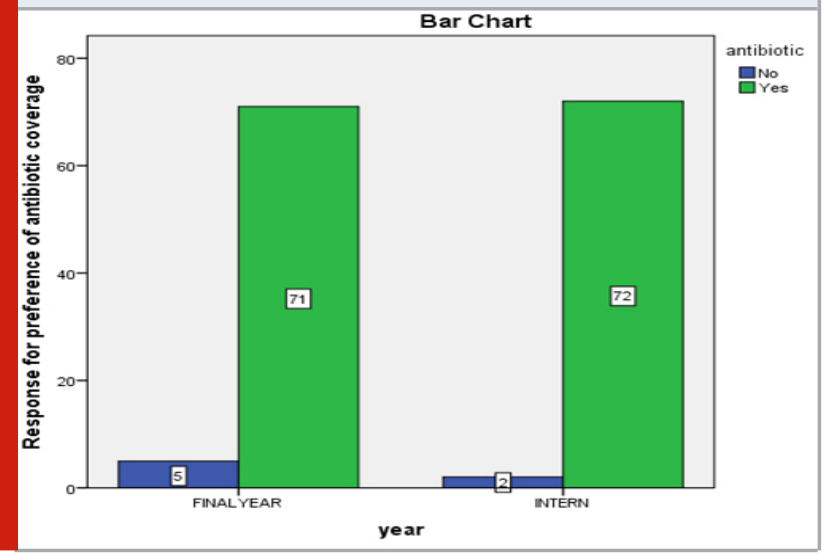

On undergoing any surgical intervention there would be release of stress adaptive hormones like catecholamines,c ortisol,glucagon which tends to lower insulin sensitivity. Henceforth it is necessary for a practitioner to ensure that the patient is under euglycemic state rather than being in hypoglycemic or hyperglycaemic state so that all these adaptive pathways are not disturbed. Patients who are under long acting forms of insulin should be switched to intermediate acting insulin about 1-2 days prior to surgical procedure. Also post operative checking for blood glucose is necessary to avoid any complications. But majority of the study population preferred going for a preoperative random blood sugar test and continuing treatment (Figure 12). Effective management of a diabetic patient begins with the dentist taking a thorough medical history and carrying out a review of systems. Dentists should collect information about the patient's recent blood glucose levels, at-home monitoring practices, frequency of $\mathrm{HbA} 1 \mathrm{C}$ tests and their readings and the 
frequency of hypo- or hyperglycemic episodes. Also, the dentist should review the current diabetes management plan, including doses and times of administration of all medications, as well as any lifestyle modifications, such as exercise or nutritional changes(Wang, 2006). Apart from this there are certain oral findings that can aid us in detecting diabetic conditions.

Figure 10: Bar graph representing the association between participants and response for duration in prescribing antibiotic coverage, where $\mathrm{X}$-axis: Year of study (Final year, Intern), Y-axis: Responses for the duration in prescribing antibiotic coverage( Blue-Both; Green-Postop; Grey-Preop).There was a statistically significant difference in the decisions for duration of prescribing antibiotics by both the categories by Chi-square test with $\mathrm{p}=0.013<$ 0.05 .

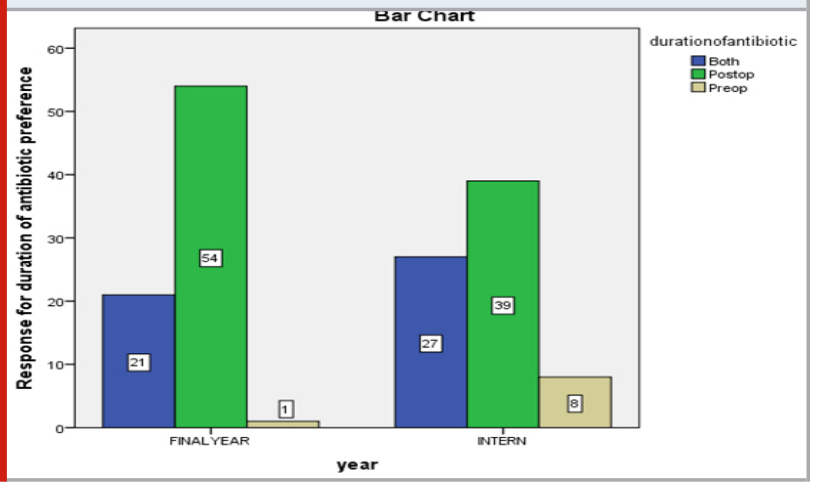

Figure-11 Bar graph representing the association between participants and response for type of antibiotic coverage prescribed, where X-axis: Year of study (Final year, Intern), Y-axis: Responses for the type of antibiotic coverage prescribed ( Blue-Amox; Green-Amox+Clav.acid; GreyAmox+Metronidazole Violet- Metronidazole). There was no statistically significant difference in the decisions for prescribing type of antibiotics by both the categories by Chi-square test with $\mathrm{p}=0.413>0.05$.

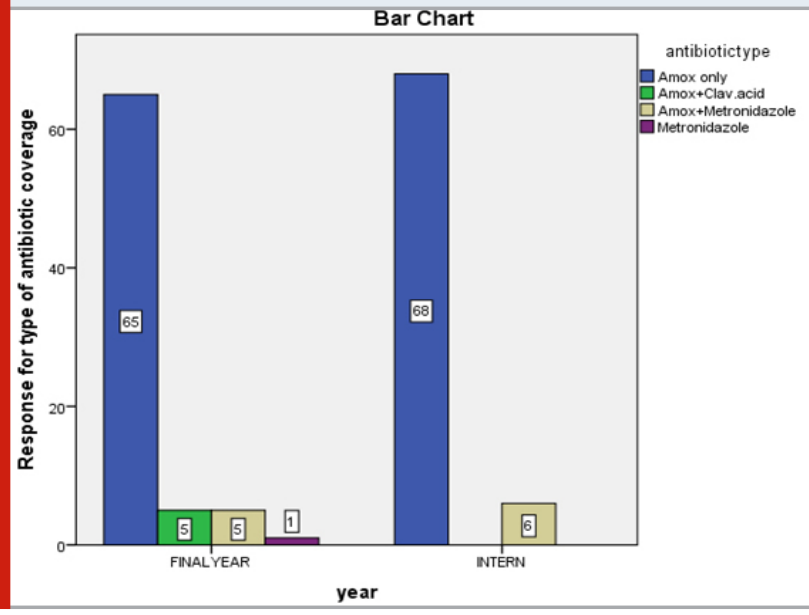

Oral manifestation of DM includes dry mouth,periodontitis, fissured tongue,burning mouth syndrome.All these features can be identified by clinical examination. Precautionary measures can be taken to eliminate post operative risk factors. There are studies stating the relation between diabetes mellitus and dental caries. The principle behind this is that the immunocompromisation in DM causes even the natural flora of the mouth to cause caries by eroding the tooth structure and further complications add due to poor hygiene and lack of control of sugars (Bovonsantijid, 1997). There are many studies in literature showing strong association between inflammation(periodontitis) and type 2 diabetes mellitus(Loe, 1993).

Figure 12: Bar graph representing the association between participants and response for type of preop test preferred, where X-axis: Year of study (Final year, Intern), Y-axis: Responses for the type of preop test preferred( BlueAll; Green-Fbs; Grey-HbA1c; Violet-Rbs).There was no statistically significant difference in the preoperative test preferred by both the categories by Chi-square test with $\mathrm{p}=0.215<0.05$.

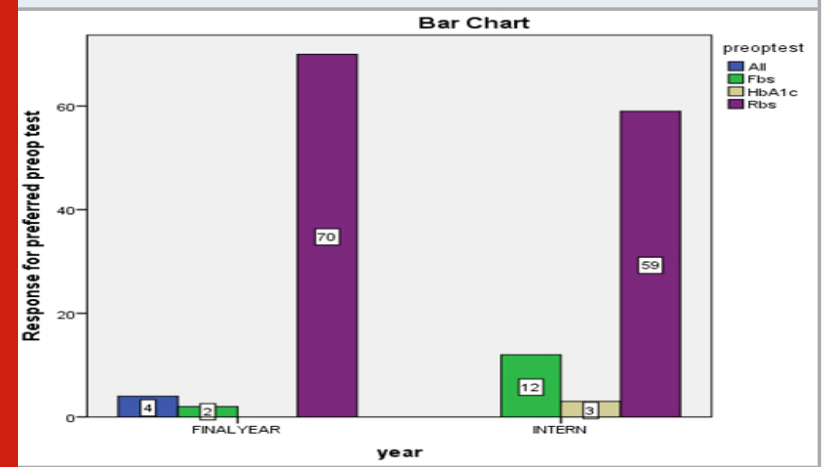

Figure-13 Bar graph representing the association between participants and response for oral finding of diabetes mellitus, where $\mathrm{X}$-axis: Year of study (Final year, Intern), Y-axis: Responses for the oral finding of diabetes mellitus( Blue-All; Green-Candidiasis; Grey-Dry mouth; Violet-Periodontitis).There was a statistically significant difference in the knowledge regarding oral indicators of diabetes by both the categories by Chi-square test with $\mathrm{p}=0.013<0.05$.

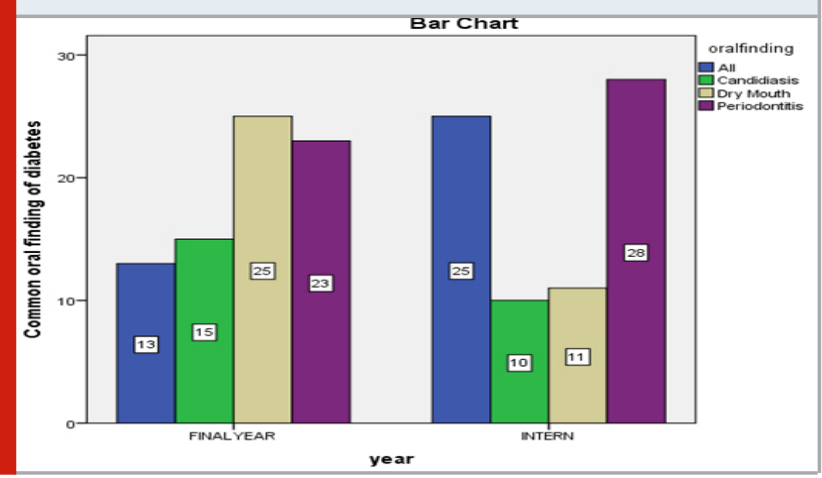

Most participants of the survey were aware of the oral indicators of diabetes mellitus (Figure 13). Oral tissue is normally protected by saliva which has slightly acidic pH.In case of diabetes there can be negative 
regulation in salivary gland function and immune system which ultimately leads to change in the $\mathrm{pH}$ resulting in periodontal inflammation which lead to further infections(Lignalli, 2009).All these changes leads to decreased salivary production resulting in dry mouth.

\section{CONCLUSION}

From this survey, it can be concluded that dental graduate students have an overall awareness on the implications of diabetes mellitus in minor oral surgical procedures. However, there lacks an in-depth understanding and patient management approaches. Also there must be similar teaching and training protocol to be followed to avoid such differences in approach to a patient. Whether continuing medical education programmes or altered teaching planner will help in better understanding and comprehensive patient management needs to be evaluated with further studies.

\section{ACKNOWLEDGMENTS}

The authors thank all the participants of this study for giving their responses independently and willingly.

Conflict of Interest: The authors declare no conflict of interest.

\section{REFERENCES}

Abdul Wahab, P. U. et al. (2017a) 'Risk Factors for Postoperative Infection Following Single Piece Osteotomy', Journal of maxillofacial and oral surgery, 16(3), pp. 328-332.

Abdul Wahab, P. U. et al. (2017b) 'Risk Factors for Postoperative Infection Following Single Piece Osteotomy’, Journal of maxillofacial and oral surgery, 16(3), pp. 328-332.

Abhinav, R. P. et al. (2019) 'The Patterns and Etiology of Maxillofacial Trauma in South India', Annals of maxillofacial surgery, 9(1), pp. 114-117.

Adeyemi, D. B. et al. (2019) 'A COMPARATIVE STUDY OF ORAL HEALTH STATUS IN DIABETIC AND NONDIABETIC PATIENTS', Oral Surgery, Oral Medicine, Oral Pathology and Oral Radiology, pp. e68-e69. doi: 10.1016/j.oooo.2019.02.165.

Akinbami, B. 0. and Godspower, T. (2014) 'Dry socket: incidence, clinical features, and predisposing factors', International journal of dentistry, 2014, p. 796102.

Benvenga, R. M. et al. (2019) 'Infective endocarditis and diabetes mellitus: Results from a single-center study from 1994 to 2017', PloS one, 14(11), p. e0223710.

Bergman, S. A. (2007) 'Perioperative management of the diabetic patient', Oral surgery, oral medicine, oral pathology, oral radiology, and endodontics, 103(6), pp. 731-737.

Bovonsantijid, Y. (1997) Microbial Infections and Elevated PGE2 as Risk Indicators of Adult Periodontitis: A Dissertation Submitted in Partial Fulfillment ... for the Degree of Doctor of Public Health (Oral Epidemiology)
Chakravarthy, P. K. (2013) 'Diabetes mellitus: An endodontic perspective', European Journal of General Dentistry, p. 241. doi: 10.4103/2278-9626.115996.

Dagogo-Jack, S. (2003) 'Preface [Hot Topic:Inflammatory Markers and Mediators: Emerging Therapeutic Targets in Diabetes, Cardiovascular and Metabolic Disorders (Guest Editor: Samuel Dagogo-Jack, MD)]', Current Drug Targets, pp. iii-iii. doi: 10.2174/1389450110304060iii. Dagogo-Jack, S. (2005) 'Management of Type 2 Diabetes in Underrepresented Minorities in the U.S', NUTRITION and DIABETES, pp. 227-248. doi: 10.1201/9781420038798-15.

Darré, L. et al. (2008) 'Efficacy of periodontal treatment on glycaemic control in diabetic patients: A meta-analysis of interventional studies', Diabetes \& metabolism, 34(5), pp. 497-506.

Eapen, B. V., Baig, M. F. and Avinash, S. (2017) 'An Assessment of the Incidence of Prolonged Postoperative Bleeding After Dental Extraction Among Patients on Uninterrupted Low Dose Aspirin Therapy and to Evaluate the Need to Stop Such Medication Prior to Dental Extractions', Journal of maxillofacial and oral surgery, 16(1), pp. 48-52.

Fasanmade, O. A., Ogunsakin, A. A. and Dagogo-Jack, S. (2019) 'Management of Diabetes Mellitus in SubSaharan Africa', Nutrition and Diabetes, pp. 349-365. doi: 10.1201/b22121-19.

Ghosh, D. (2019) 'Antibiotic Use in Dental Practice: A Review', Indian Journal of Public Health Research At Development, p. 212. doi: 10.5958/09765506.2019.03458.2.

Hariharan, R. et al. (2019) 'Oral Manifestations and Complications of Diabetes Mellitus', Indian Journal of Public Health Research \& Development. doi: 10.37506/ v10/i12/2019/ijphrd/192393.

Jain, M. and Nazar, N. (2018a) 'Comparative Evaluation of the Efficacy of Intraligamentary and Supraperiosteal Injections in the Extraction of Maxillary Teeth: A Randomized Controlled Clinical Trial', The journal of contemporary dental practice, 19(9), pp. 1117-1121.

Jain, M. and Nazar, N. (2018b) 'Comparative Evaluation of the Efficacy of Intraligamentary and Supraperiosteal Injections in the Extraction of Maxillary Teeth: A Randomized Controlled Clinical Trial', The journal of contemporary dental practice, 19(9), pp. 1117-1121. Jankhwala, S., Singh, S. and Nayak, S. (2014) 'A comparative study of profile of infections in diabetic and non-diabetic Patients', International Journal of Medical Science and Public Health, p. 982. doi: 10.5455/ ijmsph.2014.050620142.

J, P. C. et al. (2018a) 'Prevalence and measurement of anterior loop of the mandibular canal using CBCT: A cross sectional study', Clinical implant dentistry and related research, 20(4), pp. 531-534.

J, P. C. et al. (2018b) 'Prevalence and measurement of anterior loop of the mandibular canal using CBCT: A 
cross sectional study', Clinical implant dentistry and related research, 20(4), pp. 531-534.

Kidambi, S. and Patel, S. B. (2008) 'Diabetes mellitus: considerations for dentistry', Journal of the American Dental Association , 139 Suppl, p. 8S-18S.

Lignalli, A. T. (2009) Handbook of Type II Diabetes in the Middle Aged and Elderly. Nova Science Pub Incorporated.

Loe, H. (1993) 'Periodontal Disease: The sixth complication of diabetes mellitus', Diabetes Care, pp. 329-334. doi: 10.2337/diacare.16.1.329.

Marimuthu, M. et al. (2018a) 'Canonical Wnt pathway gene expression and their clinical correlation in oral squamous cell carcinoma', Indian journal of dental research: official publication of Indian Society for Dental Research, 29(3), pp. 291-297.

Marimuthu, M. et al. (2018b) 'Canonical Wnt pathway gene expression and their clinical correlation in oral squamous cell carcinoma', Indian journal of dental research: official publication of Indian Society for Dental Research, 29(3), pp. 291-297.

Patil, S. B. et al. (2017a) 'Comparison of Extended Nasolabial Flap Versus Buccal Fat Pad Graft in the Surgical Management of Oral Submucous Fibrosis: A Prospective Pilot Study', Journal of maxillofacial and oral surgery, 16(3), pp. 312-321.

Patil, S. B. et al. (2017b) 'Comparison of Extended Nasolabial Flap Versus Buccal Fat Pad Graft in the Surgical Management of Oral Submucous Fibrosis: A Prospective Pilot Study', Journal of maxillofacial and oral surgery, 16(3), pp. 312-321.

Ramadorai, A., Ravi, P. and Narayanan, V. (2019a) 'Rhinocerebral Mucormycosis: A Prospective Analysis of an Effective Treatment Protocol', Annals of maxillofacial surgery, 9(1), pp. 192-196.

Ramadorai, A., Ravi, P. and Narayanan, V. (2019b) 'Rhinocerebral Mucormycosis: A Prospective Analysis of an Effective Treatment Protocol', Annals of maxillofacial surgery, 9(1), pp. 192-196.

Rothwell, B. R. and Richard, E. L. (1984) 'Diabetes mellitus: medical and dental considerations', Special Care in Dentistry, pp. 58-65. doi: 10.1111/j.1754- 4505.1984.tb00148.x.

Sarwono, A. T. (2008) 'Sialolithiasis and Poorly Controlled Type 2 Diabetes Mellitus', Journal of Dentistry Indonesia. doi: 10.14693/jdi.v14i1.797.

S, C. and Choudhury, S. (2012) 'A Comparative Study of Thyroid Hormone and Lipid Status in Diabetic and Non Diabetic Adults', Journal of Health \& Medical Informatics. doi: 10.4172/scientificreports. 450.

Schaberg, D. S. and Norwood, J. M. (2002) 'Case Study: Infections in Diabetes Mellitus', Diabetes Spectrum, pp. 37-40. doi: 10.2337/diaspect.15.1.37.

Senthil Kumar, M. S. et al. (2019a) 'Inflammatory pseudotumour of the maxillary sinus: clinicopathological report', Oral Surgery, 12(3), pp. 255-259.

Senthil Kumar, M. S. et al. (2019b) 'Inflammatory pseudotumour of the maxillary sinus: clinicopathological report', Oral Surgery, 12(3), pp. 255-259.

Sweta, V. R., Abhinav, R. P. and Ramesh, A. (2019a) 'Role of Virtual Reality in Pain Perception of Patients Following the Administration of Local Anesthesia', Annals of maxillofacial surgery, 9(1), pp. 110-113.

Sweta, V. R., Abhinav, R. P. and Ramesh, A. (2019b) 'Role of Virtual Reality in Pain Perception of Patients Following the Administration of Local Anesthesia', Annals of maxillofacial surgery, 9(1), pp. 110-113.

Tong, D. C. and Rothwell, B. R. (2000) 'ANTIBIOTIC PROPHYLAXIS IN DENTISTRY: A REVIEW AND PRACTICE RECOMMENDATIONS', The Journal of the American Dental Association, pp. 366-374. doi: 10.14219/jada.archive.2000.0181.

Vesterinen, M. et al. (2012) 'Clinical questionnaire study of oral health care and symptoms in diabetic vs. nondiabetic predialysis chronic kidney disease patients', Clinical oral investigations, 16(2), pp. 559-563.

Wahab, P. U. A. et al. (2018) 'Scalpel Versus Diathermy in Wound Healing After Mucosal Incisions: A SplitMouth Study', Journal of oral and maxillofacial surgery: official journal of the American Association of Oral and Maxillofacial Surgeons, 76(6), pp. 1160-1164.

Wang, A. (2006) 'Diabetes mellitus and insulin therapy in infective endocarditis', European Heart Journal, pp. 3-4. doi: 10.1093/eurheartj/ehl377. 